\title{
High Protein (HP) and Balanced Diets (BD) Lead to Weight Loss and Increase of Serum Adiponectin in Obese and Overweight Women at Aerobic Gyms: A Randomized Clinical Trial
}

\author{
Reza Ghiasvand ${ }^{1}$, Pegah Amini ${ }^{1, *}$, Zahra Maghsoudi ${ }^{1}$, Awat Feizi ${ }^{2,3}$, Gholamreza Askari ${ }^{1}$ \\ ${ }^{1}$ Food Security Research Center and Department of Community Nutrition, School of Nutrition \& Food Sciences, Isfahan University of \\ Medical Sciences, Isfahan, Iran \\ ${ }^{2}$ Endocrine and Metabolism Research Center, Isfahan University of Medical Sciences, Isfahan, Iran \\ ${ }^{3}$ Department of Biostatistics \& Epidemiology, School of Health, Isfahan University of Medical Sciences, Isfahan, Iran \\ *Corresponding author: pegah4444@yahoo.com
}

Received December 23, 2014; Revised January 26, 2015; Accepted February 03, 2015

\begin{abstract}
This trial aimed to assess the effects of high protein (HP) (45\% carbohydrate, $25 \%$ protein, and $30 \%$ fat) and balanced diets (BD) (55\% carbohydrate, $15 \%$ protein, and $30 \%$ fat) on weight loss and plasma adiponectin levels in overweight and obese women who do aerobic activity. A parallel double blinded randomized clinical trial. Demographic data were collected at baseline. Body weight and adiponectin levels were measured at the baseline and after eight weeks of intervention. We used SPSS software for data analyzing and Nutritionist IV for analyzing dietary intakes. The study was an eight-week trial that consisted of 56 women with BMI $\geq 25 \mathrm{~kg} / \mathrm{m}^{2}$, aged $20-46$ years who were randomly assigned to intervention. Body weight with adherence to HP and BD diets decreased significantly, however; the reduction in the HP group was more than the $\mathrm{BD}$ group $(\mathrm{P}<0.001$ in both groups). Adiponectin significantly increased in HP and $\mathrm{BD}(\mathrm{P}=0.001$ and $\mathrm{p}<0.001$ respectively). These changes did not significantly differ between the two groups. In conclusion, our trial showed that high protein and balanced diets resulted in desirable effects on body weight and on circulating adiponectin during the eight weeks.
\end{abstract}

Keywords: diet, adiponectin, body weight

Cite This Article: Reza Ghiasvand, Pegah Amini, Zahra Maghsoudi, Awat Feizi, and Gholamreza Askari, "High Protein (HP) and Balanced Diets (BD) Lead to Weight Loss and Increase of Serum Adiponectin in Obese and Overweight Women at Aerobic Gyms: A Randomized Clinical Trial.” Journal of Food and Nutrition Research, vol. 3, no. 2 (2015): 99-103. doi: 10.12691/jfnr-3-2-4.

\section{Introduction}

Excessive fat mass storage and obesity as a disorder that is associated with energy imbalance which can lead to several chronic and degenerative diseases such as diabetes (type II), cardiovascular disease, hyperlipidemia, osteoarthritis and different kinds of cancers. [1] The dramatic increase in the prevalence of overweight and obesity emphasizes the necessity of following effective methods to control energy balance and individual body weight. Modifying physical activity and reducing energy intake of a proper macronutrients ratio are known as the most effective approaches. Recent dietary guidelines support a healthy diet plan with a macronutrients ratio of daily energy intake in the amount of more than 55\% carbohydrate, lower than $30 \%$ and $15 \%$ of fat and protein, respectively. [2] The optimal ratio of macronutrients and protein content in a diet effective in weight modification is controversial [3].

Adiponectin, an anti-inflammatory adipokine, which is produced in adipose tissue can regulate individual hunger and satiety [4] by secreting and regulating adipocytokine levels. Adiponectin acts as an indicator of metabolic change and as a link between the metabolic syndrome, obesity, insulin resistance and body fat content. [5,6] Weight gain shows indirect association with the concentration of serum adiponectin. In other words, higher fat mass especially in the abdominal area is accompanied by lower adiponectin levels $[5,6]$ and weight reduction can raise adiponectin concentrations. [7,8,9] The results of weight loss from following a high protein diet will continue as long as the subjects stay on the diet. [10] Adherence to a low-carbohydrate, high-protein diet can increase adiponectin levels and high-protein diets can lead to appetite suppression and a decrease in caloric intake. [11] However, there are limited reports on the effects of diet on serum adiponectin levels [12].

\section{Materials and Methods}

In this parallel double blinded randomized clinical trial, 56 females with age range between 20-46 years were 
recruited. The sample size was determined based on the primary information obtained from the study by Noaks $M$. et al [13] using the following formula:

$$
\begin{aligned}
& N=\frac{1+\varphi}{4}\left(\frac{Z_{(1-\alpha / 2)}+Z_{(1-\beta)}}{\Delta}\right)^{2}+\frac{Z_{(1-\alpha / 2)}^{2}}{2(1+\varphi)} \approx 25 \\
& \varphi=1, \alpha=5 \%, Z_{1-\alpha / 2}=1.96, Z_{1-\beta}=1.28, \Delta=1 .
\end{aligned}
$$

Athletes have participated in gym program, three days per week. BMI (Body mass index), which was calculated as weight $(\mathrm{kg}) /$ squared height $\left(\mathrm{m}^{2}\right)$, higher than $25 \mathrm{~kg} / \mathrm{m}^{2}$ and with no history of renal diseases, cardiovascular disorders, hypertension, dyslipidemia and diabetes mellitus were defined as inclusion criteria. Moreover, being pregnant or lactating and/or taking any supplements or drugs were defined as exclusion criteria. The trial procedure was explained to each participant, and then written informed consent was collected from all participants. The study was approved by the Research Council and Ethics Committee, Isfahan University of Medical Sciences, Isfahan, Iran. This clinical trial is registered with Iranian randomized controlled trials IRCT201402245062N7.

Study samples were assigned to two intervention groups which are defined as high protein group (HP), and control group which followed a balanced diet (BD) using permuted block randomization method. Individuals in the HP group adhered to a diet containing 45\% carbohydrate, $25 \%$ protein, and $30 \%$ fat and the $\mathrm{BD}$ group to a diet containing 55\% carbohydrate, $15 \%$ protein, and 30\% fat. All individuals followed a $500 \mathrm{kcal}$ reduction of total energy diet, which were calculated by Harris-Benedict formula for eight weeks [14].
Dietary intake was assessed by a three-day food record at baseline and every 2 weeks. Food intake was recorded at three different weekdays (the first day of the week, the middle of the week and on the weekend). Athletes weight was determined by a Seca Scale with an accuracy of 0.1 kg, with light clothing and no shoes (Seca, Model 770, and Germany). Height was measured by Seca meter with an accuracy of $0.5 \mathrm{~cm}$ in standing position, without shoes, while shoulders are in a normal position). Anthropometric measurements were assessed at baseline and eighth week of the study. Adiponectin levels were measured at baseline and at the eighth week of the study, based on standard enzyme-linked immune-sorbent assay (ELISA) using the Boster kit (Boster, Tehran, Iran). Anthropometyric and demographic variables were assessed by questionnaire. Dietary intakes were analyzed using the Nutritionist IV, Version 18 software.

Quantitative data were shown as mean \pm standard deviation and qualitative data were reflected in frequency (percent). Normality of studied variables was assessed using Kolmogorov-Smirnov (K-S) test. Positive skewed data was subjected to logarithmic transformation. Within group analysis was performed using paired samples t-test, and between group analysis was conducted using independent samples t-test, and Chi-square test was utilized to compare qualitative variables.

In some cases, where necessary, the analysis of covariance (ANCOVA) was used for adjustment. Statistical analyses in the study were performed using SPSS software (version 18; SPSS Inc., Chicago, IL, USA). $\mathrm{P}<0.05$ was defined as significant.

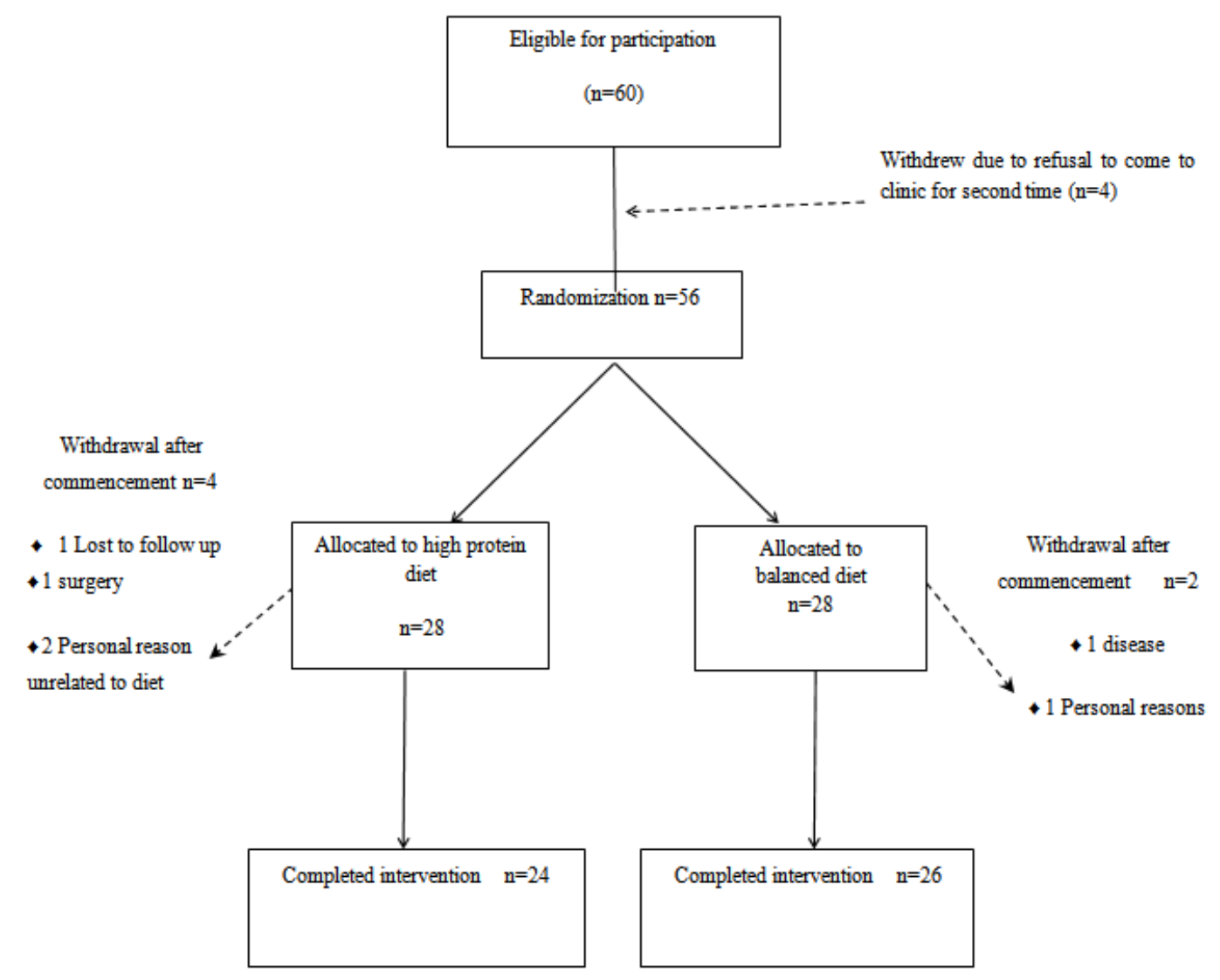

Figure 1. Study flow diagram 


\section{Results}

Demographic, anthropometric, and biochemical information of samples is demonstrated in (Table 1). Fifty six individuals were registered in the study; however, the trial was completed by 50 participants. In the present study, six individuals were excluded from the trial: one subject was not interested in completing the rest of the study, two had surgery and diseases, and three subjects did not show up for the final measurement for personal reasons. The data for the 50 subjects who completed the trial was entered for analysis (Figure 1).

At baseline, the body weight of subjects in the group with the high protein diet was higher than the individuals on the balanced diet, however subject weight were not significantly different between the two groups. Both diets lead to weight reduction, and weight differences wers statistically significant within the groups $(-2.67$ in $\mathrm{F}$ group, versus -2.35 in $\mathrm{BD})$. However, there were significant differences in weight change between the two groups.

Adherence to both diets resulted in a significant reduction in BMI, however after the intervention period,

$\mathrm{BMI}$ reduction in $\mathrm{HP}$ group was greater than $\mathrm{BD}$, nonsignificantly (change:-1.11 vs. -1.02, respectively).

Table 1. Baseline characteristics of subjects in both groups

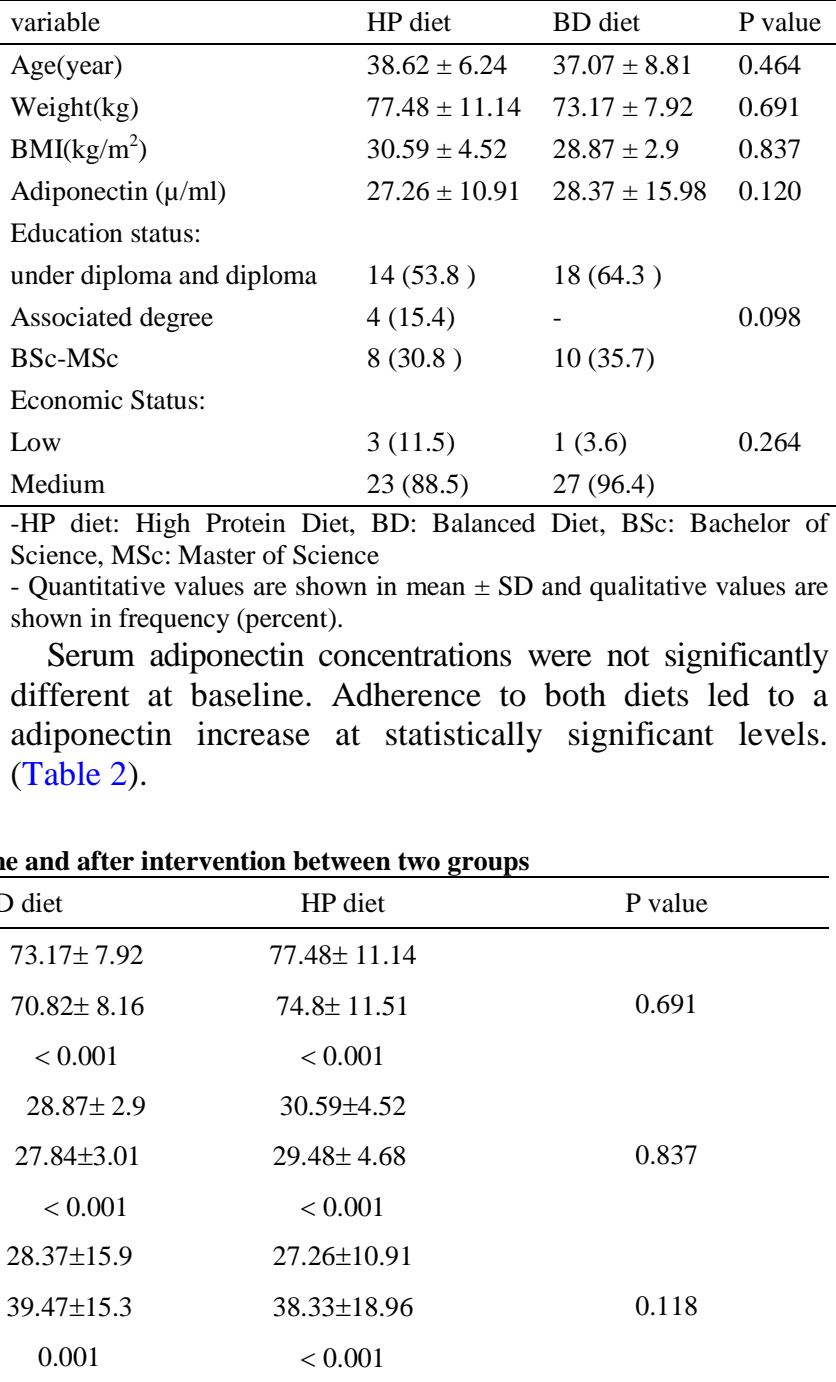

BMI: Body mass inde

BD: Balanced diet, HP: High protein diet

$\mathrm{P}<0.05$ was considered statistically significant.

Table 3. Participants' dietary intake at baseline and end of intervention in both groups

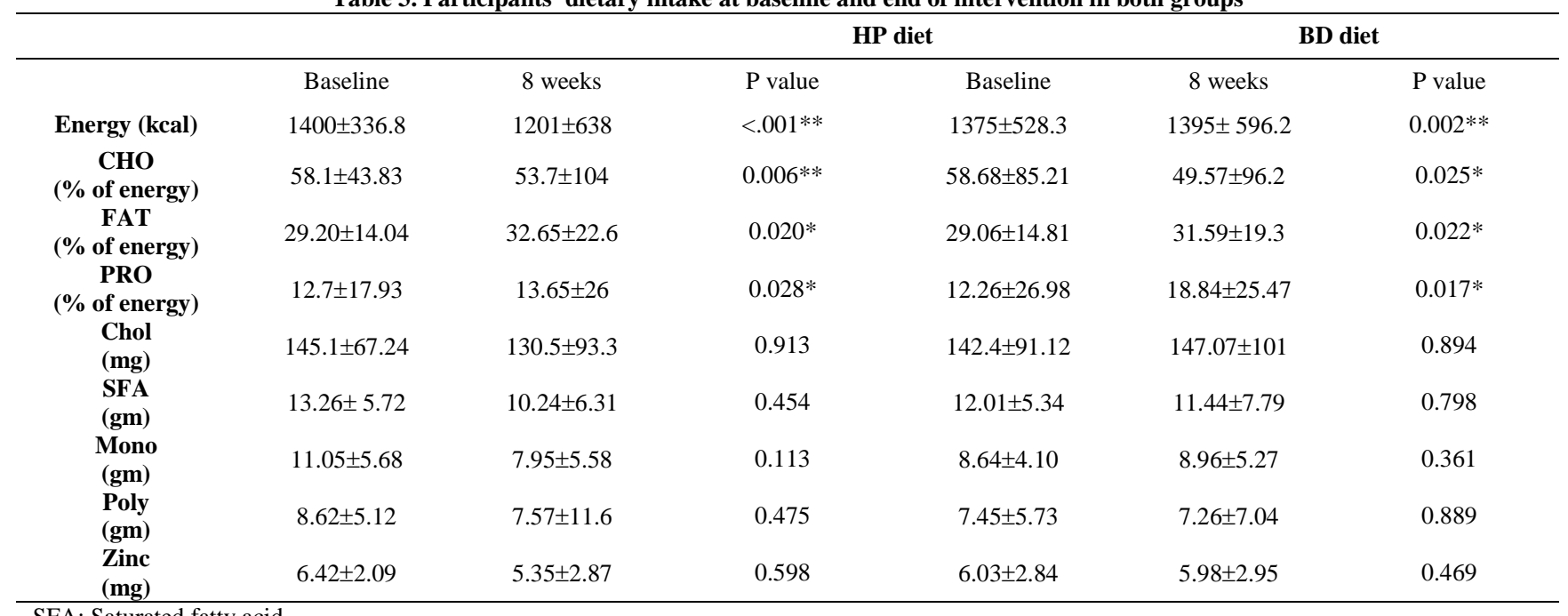

SFA: Saturated fatty acid,

Mono: Mono unsaturated fatty acid, Poly: Poly unsaturated acid.

BD: Balanced diet, HP: High protein diet.

$* \mathrm{P}<0.05$ was considered as statistically significant level.

$* * \mathrm{P}<0.001$ was considered as statistically significant level

Values are Mean \pm SD. 


\section{Discussion}

In this study, we evaluated the effects of HP and BD on weight, BMI and adiponectin levels in obese and overweight women. Data shows that both diets led to weight loss but these changes were not significant between groups. Our results are consistent with several previous studies. Krebs et al., [15] reported that adherence to a high-protein diet (40\% of total energy as carbohydrate, $30 \%$ as protein, $30 \%$ as fat) did not lead to more weight reduction than a high carbohydrate diet (55\% of total energy as carbohydrate, $15 \%$ as protein, $30 \%$ as fat).

Larsen et al., [16] showed that focusing on macronutrients composition is not an effective approach for weight reduction. Participants who consumed diets with different $\mathrm{CHO}$ to protein ratios of either 3.5 (CHO group) or 1.4 (protein group) did not lose weight at a statistically significant level. [17] While Rolland et al.,[18] indicated that weight reduction in the following lighter life diet (LL) (36\% carbohydrate, 36\% protein and 28\% fat) is higher than for a high protein - low carbohydrate diet (HPLC) (20\% carbohydrate, $40 \%$ protein and $40 \%$ fat). In a systematic review, greater weight reduction was observed on a HP diet (30\% and $40 \%$ of total energy from protein and carbohydrate, respectively) compared with a low fat- high carbohydrate (LFHC) diet (50\% from carbohydrate, $20 \%$ from protein). [19] This study stated that a high protein diet in comparison with a standard protein diet can increase an individual's satiety. [20] Krebs et al., [21] found a greater decline in BMI and weight in the following of HPLC diet (12\%, 28\%, and $59 \%$ of energy from carbohydrate, protein, and fat, respectively) compared with a low fat diet (56\% carbohydrate, $20 \%$ protein, and $24 \%$ fat). Kerksick et al., [22] stated that no significant weight reduction occurs when the intake of protein increased [low carbohydrate and high protein diet $(20 \%, 50 \%, 30 \%)$ in comparison with high carbohydrate and low protein diet (55\%, 15\%, $30 \%$ carbohydrate, protein, and fat respectively)].

Subjects in the HP diet $(40 \%$ of total energy from carbohydrate, $30 \%$ of total energy from protein, and $30 \%$ of total energy from fat) experienced more weight reduction than for a standard protein diet (SP) (55\% of energy from carbohydrate, 15\% of energy from protein, and $30 \%$ of energy from fat). [23] Generally, weight reduction studies exhibited that diets with less carbohydrate and enhanced protein content result in increased weight loss. [24] The mechanisms that support more weight reduction in the following of higher protein diets are still unclear; however, researchers speculated that greater weight reduction may be associated with more energy expenditure, greater satiety [25], and increased dietary fat oxidation in subjects who adhere to higher protein diets [26].

According to our results, following both diets lead to significant increase in adiponectin levels; however, there was no significant difference between Hp, BD groups.

Adiponectinis is an adipocytokine which shows an indirect relation with metabolic syndrome features. [27]

Sofer et al., [28] believed that a rise in adiponectin concentrations is a main factor in modifying glucose balance and inflammation factors. Rolland et al., [18] reported that following a lighter life diet (36\% of energy from carbohydrate, 36\% of energy from protein, and $28 \%$ of energy from fat) leads to a higher change in inflammatory factors and adiponectin levels than a low carbohydrate-high protein diet (20\% carbohydrate, 40\% protein, and $40 \%$ fat) in obese subjects. Christiansen et al., [29] proposed that concerning gender differences, plasma concentrations of adiponectin were enhanced in females compared with males. Moreover, they recognized a higher expression of adiponectin in females compared with males. Peake et al., [30] detected that after a high fat and lowcarbohydrate meal (19 g carbohydrate, 80 g dietary fat, and 47 g protein), plasma adiponectin levels showed no significant changes in two groups (normal subjects and patients with type II diabetes). Paniagua et al., [31] reported that serum adiponectin lowered after a low-fat and high-carbohydrate diet (65\% carbohydrate, 20\% fat, and $15 \%$ protein) in comparison with a high fat diet $(47 \%$ CHO, $38 \%$ fat and $15 \%$ protein). In a study by Ruth et al., [32] a high-protein, low-carbohydrate (HPLC) diet (33.5\% protein, $56 \%$ fat, and $9.6 \%$ carbohydrate) showed a significant increase in adiponectin concentrations compared with low-protein, high- carbohydrate (LPHC) diet (22\% protein, $25 \%$ fat, $55.7 \%$ carbohydrate).

It appears that an increase in adiponectin levels depends on the type of diet and its content ratios. As far as we know, there has not been a study that assesses the effects of HP diet on adiponectin concentration. Both diets (HP and $\mathrm{BD}$ ) led to increasing levels of circulating adiponectin significantly; however these differences were not significant between the two groups. There is a requirement for more trials in this area with higher sample size, and various protein content ratio percentages of total energy intake. Several limitations in the current study require to be considered. First, we conducted our study on overweight and obese women, and it seems unlikely to be able to generalize our findings to the general population. Second, measurement error and bias of food records could have an impact on our observed relationship. Third, the short period of the trial can affect the observed relationship.

\section{Conclusion}

A HP diet and a balanced diet can lead to significant desirable effects on body weight and circulating adiponectin; however these changes did not differ between the two groups (HP diet and balanced diet) significantly and also these effects were not significant after adjustment. There is need for more powerful experiments in this area with a higher sample size.

\section{Conflict of Interest}

The authors had no conflicts of interest.

\section{Acknowledgements}

The study was designed by RGH, GHA; data were collected and analyzed by PA, AF, ZM; data interpretation and manuscript preparation were undertaken by PA, ZM, $\mathrm{RGH}$, and $\mathrm{MH}$. All authors approved the final version of paper. 
This study extracted from MSc dissertation, approved by Ethical Committee of Isfahan University of Medical Sciences (code 392233).

\section{Competing Interests}

This study is funded by Vice Chancellor for Research, Isfahan University of Medical Science.

The authors have no competing interests.

\section{References}

[1] Must, A., Spadano, J., Coakley, E.H., Field, A.E., Colditz, G., Dietz, W.H, "The disease burden associated with overweight and obesity," J Am Med Assoc, 282. 1523-1529. 1999.

[2] "American Heart Association Scientific Statement AHA D Guidelines Revision," Circulation, 102. 2284-2299.2000.

[3] Hu, F.B., Stampfer, M.J., Manson, J.E., et al, "Dietary protein and risk of ischemic heart disease in women," Am J Clin Nutr, 70. 221-227. 1999.

[4] Ronti, T., Lupattelli, G., Mannarino, E, "The endocrine function of adipose tissue: an update," Clin Endocrinol (Oxf), 64. 355-365. 2006.

[5] Matsuzawa, Y, "Establishment of a concept of visceral fat syndrome and discovery of adiponectin," Proc Jpn Acad Ser B Phys Biol Sci, 86. 131-141. 2010.

[6] Koh, S.B., Yoon, J., Kim, J.Y., Yoo, B.S., Lee, S.H., Park, J.K, "Relationships between serum adiponectin with metabolic syndrome and components of metabolic syndrome in nondiabetic Koreans ARIRANG study," Yonsei Med J, 52. 234-241. 2011.

[7] Yildiz, B.O., Suchard, M.A., Wong, M.L., McCann, S.M., Licinio, $\mathrm{J}$, "Alterations in the dynamics of circulating ghrelin, adiponectin, and leptin in human obesity", Proc Natl Acad Sci USA, 101. 10434 -10439. 2004.

[8] Ueno, H., Yamaguchi, H., Kangawa, K., Nakazato, M, "Ghrelin: a gastric peptide that regulates food intake and energy homeostasis", Regul Pept, 126. 11-19. 2005.

[9] Wells, T, "Ghreline defender of fat," Prog Lipid Res, 48. 257 2009.

[10] Skov, A.R., Toubro, S., Ronn, B., Holm, L., Astrup, A," Randomized trail on protein vs carbohydrate in ad libitum fat reduced diets for the treatment of obesity," Int J Obes Relat Metab Disord, 23. 528-536. 1999.

[11] Taubes, G," Nutrition: The soft science of dietry fat," Science, 29, 2536-2545, 2001.

[12] Ratliff, J.C., Mutungi, G., Puglisi, M.J., Volek, J.S., Fernandez, M.L, "Eggs modulate the inflammatory response to carbohydrate restricted diets in overweight men," Nutr Metab (Lond), 5, 46-55, 2008.

[13] Noakes, M., Keogh, J.B., Foster, P.R., Clifton, P.M, "Effect of an energy restricted, high protein, low fat diet relative to a conventional high carbohydrate, low fat diet on weight loss, body composition, nutritional status, and markers of cardiovascular health in obese women," Am J Clin Nutr, 81, 1298-1306, 2005.

[14] Sargrad, K.R., Homko, C., Mozzoli, M., Boden, G, "Effect of High Protein vs High Carbohydrate Intake on Insulin Sensitivity, Body Weight, Hemoglobin A1c, and Blood Pressure in Patients with Type 2 Diabetes Mellitus," J Am Diet Assoc, 105, 573-580, 2005.

[15] Krebs, N.F., Gao, D., Gralla, J., Collins, J.S., Johnson, S.L, "The Diabetes Excess Weight Loss (DEWL) Trial: a randomized controlled trial of high-protein versus high-carbohydrate diets over 2 years in type 2 diabetes," Diabetologia, 55, 905-914, 2012.

[16] Larsen, R.N., Mann, N.J., Maclean, E., Shaw, J.E, "The effect of high-protein, low-carbohydrate diets in the treatment of type 2 diabetes: a 12 month randomized controlled trial," Diabetologia, 54, 731-740, 2011.

[17] Layman, D.K., Boileau, R.A., Erickson, D.J., Painter, J.E., Shiue, H., Sather, C, "A Reduced Ratio of Dietary Carbohydrate to Protein Improves Body Composition and Blood Lipid Profiles during Weight Loss in Adult Women," J Nutr, 133, 411-417, 2003.

[18] Rolland, C., Hession, M., Broom, I, "Effect of weight loss on adipokine levels in obese patients," Diabetes, Metabolic Syndrome and Obesity: Targets and Therapy, 4, 315-323, 2011.

[19] Hession, M., Rolland, C., Kulkarni, U., Wise, A., Broom, J, "Systematic review of randomized controlled trials of lowcarbohydrate vs. low-fat/low-calorie diets in the management of obesity and its comorbidities," Obesity Reviews, 10, 36-50, 2009.

[20] Jenkins, D.J., Wong, J.M., Kendall, C.W., Esfahani, A., Leong, T.C., Faulkner, D.A, "The effect of a plant based lowcarbohydrate ("Eco-Atkins") diet on body weight and blood lipid concentrations in hyperlipidemic subjects," Arch Intern Med, 169, 1046-1054, 2009.

[21] Krebs, N.F., Gao, D., Gralla, J., Collins, J.S., Johnson, S.L, "Efficacy and Safety of a High Protein, Low Carbohydrate Diet for Weight Loss in Severely Obese Adolescents," J Pediatr, 157, 252-258, 2010.

[22] Kerksick, C.M., Wismann-Bunn, J., Fogt, D., Thomas, A.R., Taylor, L., Campbell, B.I, "Changes in weight loss, body composition and cardiovascular disease risk after altering macronutrient distributions during a regular exercise program in obese women," Nutr J, 9, 59-78, 2010.

[23] Evangelista, L.S., Heber, D., Zhaoping, L.i., Bowerman, S., Hamilton, M.A, \& Fonarow, G.C, "Reduced Body Weight and Adiposity with a High-Protein Diet Improves Functional Status, Lipid Profiles, Glycemic Control, and Quality of Life in Patients with Heart Failure," J Cardiovasc Nurs, 24(3), 207-215, 2009.

[24] Foster, G.D., Wyatt, H.R., Hill, J.O., McGuckin, B.G., Brill, C., Mohammed BS: A randomized trial of a low-carbohydrate diet for obesity," N Engl J Med, 348, 2082-2090, 2003.

[25] Weigle, D.S., Breen, P.A., Matthys, C.C., Callahan, H.S., Meeuws, K.E., Burden, V.R, "A high-protein diet induces sustained reductions in appetite, ad libitum caloric intake, and body weight despite compensatory changes in diurnal plasma leptin and ghrelin concentrations," Am J Clin Nutr, 82, 41-48, 2005.

[26] Adam-Perrot, A., Clifton, P., Brouns, F, "Low-carbohydrate diets: nutritional and physiological aspects," Obes Rev, 7, 49-58, 2006.

[27] Havel, P.J, "Update on adipocyte hormones: regulation of energy balance and carbohydrate/lipid metabolism," Diabetes, 53, Suppl. 1, S143-S151, 2004

[28] Sofer, S., Eliraz, A., Kaplan, S., Voet, H., Fink, G., Kima, T, "Greater weight loss and hormonal changes after 6 months diet with carbohydrates eaten mostly at dinner," Obesity (Silver Spring), 19, 2006-2014, 2011.

[29] Christiansen, T., Paulsen, S.K., Bruun, J.M., Ploug, T.h., Pedersen, S.B., and Richelsen, B, "Diet-Induced Weight Loss and Exercise Alone and in Combination Enhance the Expression of Adiponectin Receptors in Adipose Tissue and Skeletal Muscle, but Only DietInduced Weight Loss Enhanced Circulating Adiponectin," J Clin Endocrinol Metab, 95, 911-919, 2010.

[30] Peake1, P.W., Kriketos, A.D., Denyer, G.S., Campbell, L.V \& Charlesworth, J.A, "The postprandial response of adiponectin to a high-fat meal in normal and insulin-resistant subjects," Int $J$ Obesity, 27, 657-662, 2003.

[31] Paniagua, J.A, sacristana, A.G., Romero, I., Vidal-puig, A., Latre, J.M, "Monounsaturated Fat-Rich Diet Prevents Central Body Fat Distribution and Decreases Postprandial Adiponectin Expression Induced by a Carbohydrate- Rich Diet in Insulin-Resistant Subjects," Diabetes Care, 30, 1717-1723, 2007.

[32] Ruth, M.R., Port, A.M., Shah, M., Bourland, A.C., Istfan, N.W., Nelson, K.P, "Consuming a hypocaloric high fat low carbohydrate diet for 12 weeks lowers C-reactive protein, and raises serum adiponectin and high density lipoprotein-cholesterol in obese subjects," Metabolism, 62(12), 1779-1787, 2013. 